\title{
EDUCAÇÃO ESPECIAL E POLÍTICAS DE INCLUSÃO ESCOLAR EM SANTA MARIA, RIO GRANDE DO SUL (2007-2015)
}

\author{
Aline Castro Delevati ${ }^{1}$ (D) \\ Melina Chassot Benincasa Meirelles ${ }^{1}$ \\ Claudio Roberto Baptista ${ }^{1}$ \\ Cláudia Rodrigues de Freitas ${ }^{l}$
}

\begin{abstract}
RESUMO: O texto analisa os movimentos institucionais que caracterizam a política de inclusão escolar em Santa Maria, no Rio Grande do Sul. O pensamento sistêmico e o ciclo de políticas constituem o referencial teórico que auxiliou na análise dos dados de matrículas, documentos normativos, produçóes acadêmicas e entrevistas. A pesquisa permitiu-nos identificar a ampliação do acesso e permanência de alunos com deficiência e serviços que favorecem a sua escolarização em classes comuns indícios de uma prática centrada no ensino colaborativo com vistas ao acesso ao currículo.
\end{abstract}

Palavras-chave: Política educacional. Inclusão escolar. Santa Maria. Rio Grande do Sul. Ciclo de políticas.

\section{Special education and politics of scholar inclusion in Santa Maria, Rio Grande do Sul, Brazil (2007-2015)}

ABSTRACT: This text analyzes the institutional movements that characterize the politic of scholar inclusion in Santa Maria,

\footnotetext{
${ }^{1}$ Universidade Federal do Rio Grande do Sul - Porto Alegre (RS), Brasil.

Emails: alinedelevati@hotmail.com; melinabenincasa@gmail.com;

baptistacaronti@yahoo.com.br; freitascrd@gmail.com

DOI: 10.1590/CC0101-32622018195360
} 
Rio Grande do Sul, Brazil. The systemic thinking and the policy cycle constitute the theoretical framework that helped us to examine school enrollment, normative documents, academic production and interviews. The research allowed us to identify not only the expansion of the access and permanence of students with disabilities, but also the services that favor their schooling in common classes - an indication of a practice centered on collaborative teaching regarding the access to the curriculum.

Keywords: Educational policy.Scholar inclusion. Santa Maria. Rio Grande do Sul. Policy cycle.

\section{INTRODUÇÃO}

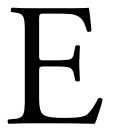

ste texto apresenta uma análise sobre as políticas de inclusão escolar em Santa Maria, no Rio Grande do Sul. A pesquisa associa-se a um conjunto de iniciativas que têm como interesse central o conhecimento acerca dos serviços especializados oferecidos aos alunos com deficiência, transtornos globais do desenvolvimento e altas habilidades/superdotação ${ }^{1}$ que frequentam as escolas municipais, no estado do Rio Grande do Sul. No âmbito dessas reflexóes, desenvolve-se uma abordagem prioritária da política educacional do sistema municipal, no entanto a análise procura mostrar também o contexto do município de Santa Maria, com suas diferentes redes de ensino.

No presente estudo, destacamos Santa Maria buscando identificar os movimentos institucionais que caracterizam a política de inclusão escolar, com ênfase na rede municipal de ensino, com vistas a oferecer uma leitura atualizada da política dessa rede, por meio do acompanhamento de sua trajetória, do conhecimento de suas diretrizes e da análise dos possíveis efeitos no cotidiano e na prática pedagógica.

Iniciamos com a apresentação da base epistemológica da investigação, com especial atenção dirigida ao referencial teórico que confere sustentação à análise das políticas. Ressaltamos, ainda, os passos metodológicos que orientaram essas reflexóes e a discussão necessária a ser 
estabelecida entre o atual momento da rede em questão com o macrocontexto da política nacional em pauta.

Partimos da concepção de política como um constructo social (MULLER; SUREL, 2002), um processo inacabado, tecido em um tempo e espaço por meio das relaçóes e tensôes de diversos atores (BOWE; BALL; GOLD, 1992).

A fim de compreendermos os movimentos das políticas de inclusão escolar no município de Santa Maria, baseamo-nos no reconhecimento de seu caráter complexo, dinâmico, singular e impreciso. Assim, entendemos não existir uma única realidade a ser desvelada, mas múltiplos olhares associados ao processo de intervenção e atribuição de sentidos, os quais possibilitam diversas interpretaçóes dos fenômenos investigados. Essa perspectiva encontra ainda suas bases no reconhecimento de que inexiste uma realidade prévia a ser descoberta, independentemente do observador, como afirmam Maturana e Varela (2001). A compreensão relativa à complexidade dos fenômenos associa-se à valorização da intersubjetividade como processo que integra $\mathrm{o}$ ato de investigar, exigindo que o observador seja identificado como parte integrante dos fenômenos analisados (BAPTISTA, 2009).

$\mathrm{Na}$ análise de uma política, torna-se imprescindível, portanto, considerar a articulação entre macro e microcontextos, ou seja, as influências nacionais e internacionais e sua relação em um contexto local (redes de ensino, escolas, salas de aula etc.). Assim, faz-se necessário dar ênfase a uma abordagem analítica dessa política capaz de teorizá-la e compreendê-la levando em conta a dinâmica de sua constituição (BRIZOLLA, 2007).

Segundo Ball (1994), as políticas são mediações codificadas de forma complexa mediante embates, acordos, interpretaçóes e reinterpretaçóes por parte das autoridades públicas. São decodificadas também de maneira complexa, pela interpretaçáo dos atores envolvidos, atribuindo significados em função de suas histórias, experiências e possibilidades (BALL, 1994, p. 16). Com essa definição, o autor designa a política como texto e, ainda, como discurso. Logo, políticas são intervenções textuais, mas também carregam limitaçóes materiais e possibilidades.

Para Ball e Mainardes (2011), as condições, os recursos, as histórias e os compromissos locais são diferentes e, por isso, a realização da política vai diferir. As políticas, particularmente as educacionais, em geral 
são pensadas e escritas para contextos que possuem infraestrutura e condiçôes de trabalho adequadas, sem levar em conta as enormes variaçóes de contexto, de recursos, de desigualdades regionais ou das capacidades locais (BALL; MAINARDES, 2011, p. 13).

Os autores ainda salientam a importância da análise dos aspectos locais, na busca de identificar características particulares, especificidades e arenas competitivas significativas à realização das políticas.

No que diz respeito à dimensão metodológica, é importante destacar que, ao elaborar nossas reflexóes, nos fundamentamos na compreensão dessas arenas como expressão de dimensóes que podem parecer contraditórias, pois são processos constituídos de açóes diferenciadas, em uma dinâmica construtiva que faz referência contínua à coconstrução como constructo interpretativo. $\mathrm{O}$ presente texto é fruto de um estudo de natureza qualitativa que, além da análise documental, utiliza diferentes fontes, inclusive indicadores quantitativos, como indícios de uma realidade complexa em contínua transformação.

Para a elaboração da presente análise, produzimos e sistematizamos informaçóes referentes aos dados de matrícula da rede pública de ensino regular e ensino especial ${ }^{2}$. Ao considerarmos os indicadores relativos ao ensino especial, apresentaremos, ainda, os dados de matrículas da rede privada. Nosso foco de análise são as matrículas das redes públicas de ensino (municipal e estadual), porém, no que se refere às matrículas dos alunos público-alvo da educaçâo especial, acreditamos ser imprescindível associar tais dados àqueles concernentes à rede privada, que oferece serviços de atendimento exclusivo em educaçáo especial. No Rio Grande do Sul, há um movimento crescente e numericamente significativo de matrículas desses alunos no ensino regular (BAPTISTA, 2015). No entanto existe também um contingente de alunos que permanecem com matrículas exclusivas no ensino especial, em sua maioria em instituiçóes privadas, filantrópicas e conveniadas com o poder público.

O cenário descrito é constitutivo de uma realidade em forte processo de mudança, que tem sido respaldado pelas alteraçóes dos dispositivos normativos que, depois de 2009, passaram a exigir que as redes de ensino organizem a escolarização dos alunos com deficiência nos espaços regulares do ensino comum (BRASIL, 2009). Trata-se de um processo complexo, por envolver um país com grandes diferenças regionais, diversificadas con- 
figurações na oferta de serviços educacionais, e, sobretudo, por exigir que sejam instituídas novas formas de compreensão acerca da deficiência, dos procedimentos avaliativos, da busca de sintonia entre serviços que assegurem a participação social e a aprendizagem. As políticas de inclusão escolar no Brasil têm mostrado que as alteraçóes ocorrem em modo progressivo e que, no âmbito dos serviços educacionais, se deixa de valorizar aqueles de caráter exclusivo - classes especiais e escolas especiais - para investir em outros que se mostram integrados à escola de ensino comum, como as salas de recursos. Tais salas, como um dispositivo pedagógico central na oferta do apoio especializado, passam a integrar um dos programas ministeriais que se difundem por meio das iniciativas dos municípios brasileiros como parte de uma série de programas que visam à implementaçáo da política de inclusão escolar no país (BAPTISTA, 2011).

As reflexóes apresentadas aqui estão vinculadas à pesquisa que investiga as políticas de inclusão escolar, considerando o acesso às matrículas do censo escolar da educação básica no período de 2007 a $2015^{3}$. A investigação foi realizada predominantemente com base na análise documental de dispositivos normativos e orientadores da política, além de produçóes acadêmicas que analisam processos semelhantes. Contamos ainda, em modo complementar, com entrevistas ${ }^{4}$ dirigidas ao gestor responsável pela educação especial no município de Santa Maria e com a uma professora do atendimento educacional especializado, realizadas em 2015, tendo como foco base a organização da rede, os serviços instituídos, e o perfil dos alunos e dos profissionais da educação.

Com o objetivo de contextualizar as informaçóes, iniciamos pelos índices de matrículas no estado do Rio Grande do Sul dos alunos público-alvo da educação especial no ensino regular e no ensino especial. Posteriormente, passamos para o microcontexto de Santa Maria.

Podemos observar no Gráfico 1 que existe uma inversão da tendência histórica de predomínio das matrículas no ensino especial a partir de 2008. Observam-se intensa elevação das matrículas no ensino regular e alteraçóes no ensino especial, indicando declínio, uma vez que essas matrículas totalizavam 26.002 alunos em 2007, passando, em 2015, ao total de 14.277 matrículas. Alteração mais significativa pode ser constatada nas matrículas do público-alvo da educação especial no ensino regular, passando de 15.268 em 2007 para 58.341 no ano de 2015 . 
Em 2015, segundo o censo escolar da educação básica, o Rio Grande do Sul contava com 1.752.075 matrículas no ensino regular, distribuídas nas redes públicas, sendo 866.989 na rede estadual e 885.086 nas redes municipais. Nessas redes de ensino, a presença de alunos com deficiência em classes comuns era, respectivamente, igual a 25.470 e 32.871. Quando consideramos as matrículas de alunos com deficiência no ensino especial (classes e escolas especiais), identificamos, em 2015, 1.617 matrículas na rede estadual, 1.681 nas redes municipais e 10.979 na rede privada de ensino, totalizando 14.277 matrículas.

\section{A POLÍTICA DE INCLUSÃO ESCOLAR EM SANTA MARIA}

Santa Maria é um município localizado na região central do estado do Rio Grande do Sul, com cerca de 280 mil habitantes, segundo estimativas do Instituto Brasileiro de Geografia e Estatística (IBGE) em 2015. É a quinta cidade mais populosa do estado, sendo considerada polo educacional de grande expressão rio-grandense, com destaque para a Universidade Federal de Santa Maria (UFSM).

\section{Gráfico 1}

Matrículas gerais do público-alvo da educação especial no estado do Rio Grande do Sul no ensino regular e no ensino especial: 2007 a 2015.

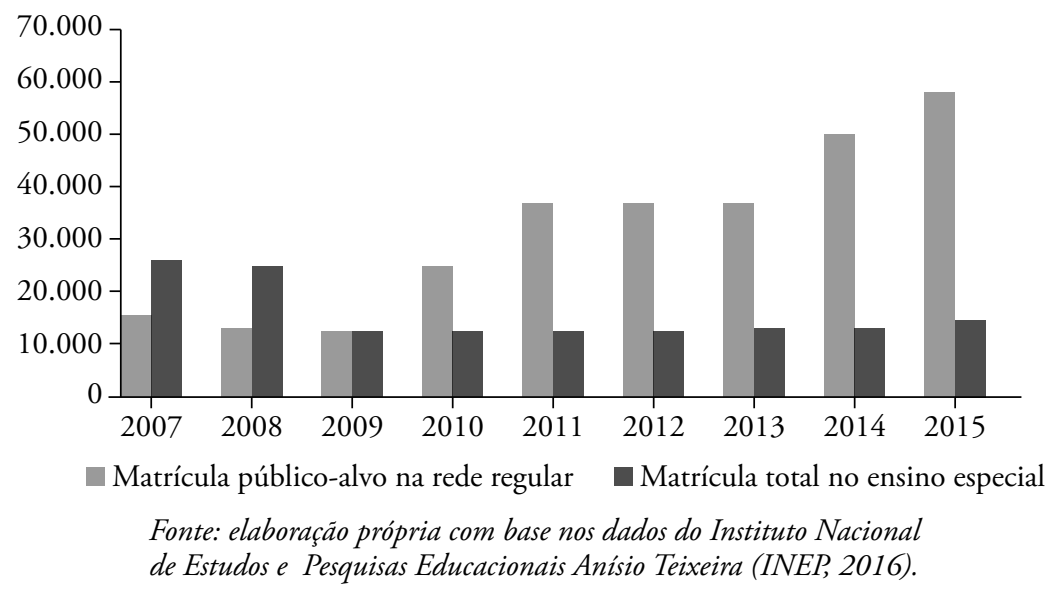


De acordo com os dados do censo escolar de 2014, a rede municipal de educação era constituída de 77 escolas de ensino regular 20 instituições de educação infantil, três escolas de educação infantil conveniadas e 54 de ensino fundamental. Do universo das escolas de ensino fundamental, 31 ofertavam educação infantil.

No que diz respeito ao corpo docente ${ }^{5}$ da rede municipal, em $2013^{6}$ eram 2.922 professores $^{7}$, dos quais 226 atuavam na educação infantil e 2.696 no ensino fundamental. Em relação à presença de salas de recursos e à oferta do atendimento educacional especializado na rede municipal, ambos eram observados em 49 escolas: 44 de ensino fundamental e 5 de educação infantil.

Traçando um comparativo de Santa Maria com o Rio Grande do Sul e com o Brasil, percebemos que a variação das matrículas do ensino regular seguiu a tendência do estado e do país após 2008, em um momento em que houve a disseminação das diretrizes da Política Nacional de Educação Especial na Perspectiva da Educação Inclusiva. O Gráfico 2 ilustra esse processo, bem como demonstra que Santa Maria apresenta percentual superior ao do estado e do país, quando destacados

\section{Gráfico 2}

Porcentagem de matrículas de alunos com deficiência, transtornos globais de desenvolvimento e altas habilidades ou superdotação em classes comuns.

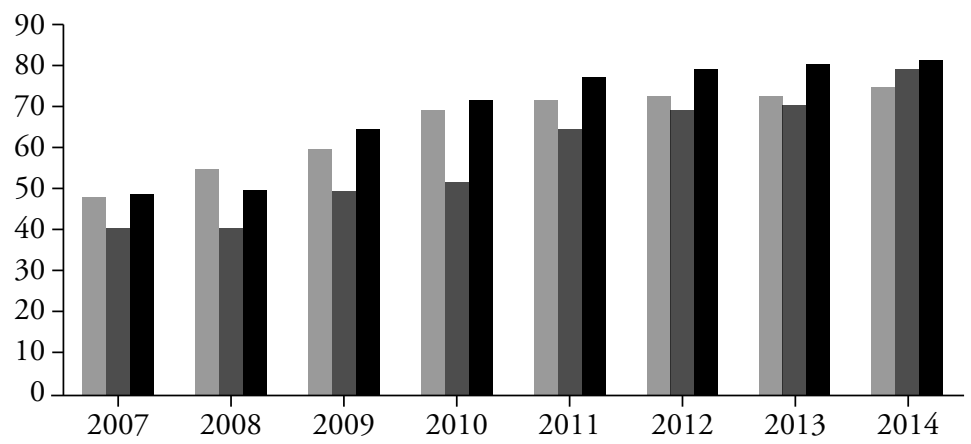

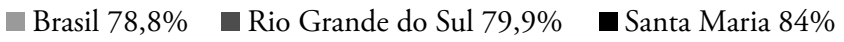

Fonte: elaboração própria com base nos dados do Instituto Nacional de Estudos e Pesquisas Educacionais Anisio Teixeira (INEP, 2016). 
os índices de matrículas de alunos com deficiência em classes comuns do ensino regular.

Considerando esses índices, optamos por oferecer ao leitor informaçóes sobre como se distribuem, no município, as matrículas nas redes públicas - estadual e municipal —, a fim de favorecer a contextualização. Para facilitar a compreensão dos dados, organizamos tabelas com algumas diretrizes de análise: na educação regular, foram levados em conta os números totais de matrículas da rede pública de ensino e respectivas matrículas do público-alvo da educação especial.

Podemos observar, em ambos os cenários, a redução das matrículas totais e o aumento das matrículas dos alunos com deficiência. Ao pensarmos na relação entre o total de matrículas e aquelas específicas dos alunos público-alvo da educação especial no ano de 2015 , encontra-se percentual semelhante a $4 \%$ desses alunos para ambas as redes de

\section{Tabela 1}

Matrículas do ensino regular do município de Santa Maria (classes comuns): rede estadual e rede municipal × público-alvo da educação especial, 2007 a 2015.

\begin{tabular}{|c|c|c|c|c|c|}
\hline \multirow{2}{*}{ Ano } & \multicolumn{2}{|c|}{$\begin{array}{c}\text { Rede estadual de } \\
\text { ensino em Santa Maria }\end{array}$} & \multicolumn{2}{|c|}{$\begin{array}{c}\text { Rede municipal de } \\
\text { ensino em Santa Maria }\end{array}$} & \multirow{2}{*}{$\begin{array}{c}\text { Matrículas } \\
\text { totais }\end{array}$} \\
\hline & $\begin{array}{l}\text { Matrículas } \\
\text { totais }\end{array}$ & $\begin{array}{l}\text { Público-alvo da } \\
\text { educaçáo especial }\end{array}$ & $\begin{array}{c}\text { Matrículas } \\
\text { totais }\end{array}$ & $\begin{array}{l}\text { Público-alvo da } \\
\text { educaçáo especial }\end{array}$ & \\
\hline 2007 & 24.177 & 232 & 17.792 & 237 & 41.969 \\
\hline 2008 & 23.215 & 274 & 17.490 & 226 & 40.705 \\
\hline 2009 & 22.623 & 224 & 17.382 & 387 & 40.005 \\
\hline 2010 & 21.725 & 340 & 17.440 & 490 & 39.165 \\
\hline 2011 & 20.691 & 368 & 17.269 & 497 & 37.960 \\
\hline 2012 & 20.470 & 481 & 16.937 & 569 & 37.407 \\
\hline 2013 & 19.636 & 535 & 16.916 & 644 & 36.552 \\
\hline 2014 & 18.949 & 614 & 16.669 & 641 & 35.618 \\
\hline 2015 & 18.001 & 737 & 16.445 & 655 & 34.446 \\
\hline
\end{tabular}

Fonte: elaboração própria com base nos dados do Instituto Nacional de Estudos e Pesquisas Educacionais Anisio Teixeira (INEP, 2016). 
ensino. Apesar do avanço quanto ao aumento de matrículas de educandos com deficiência nas escolas de Santa Maria, muitos deles não frequentam as classes comuns do ensino regular, como vemos na Tabela 2 .

Contrariamente ao aumento das matrículas no ensino regular, observa-se, no período analisado, redução das matrículas no ensino especial nas três redes de ensino. Ao longo dos nove anos, o total das matrículas do ensino especial no município passou de 564 para 270, confirmando a tendência nacional. Verifica-se ainda que, desde 2008, inexistem matrículas na rede municipal, após o fechamento de classes e escolas especiais, contudo as redes estaduais e privadas mantêm o ensino especial (exclusivo), com, ainda, o total de 115 matrículas na rede estadual e 155 na rede privada no ano de 2015. Quando se analisa a tipologia dessas matrículas, identifica-se a sintonia com a tendência estadual, em que os alunos surdos estão em escolas especiais públicas ou privadas, com prevalência na rede estadual em Santa Maria.

Para compreendermos melhor os aspectos locais, as perspectivas e as tendências, passamos a analisar alguns documentos de destaque na política local. O material Diretrizes Curriculares para a Educação

\section{Tabela 2}

Matrículas no ensino especial nas redes estadual, municipal e privada: 2007 a 2015, em Santa Maria (RS).

\begin{tabular}{l|c|c|c|c}
\hline & Rede estadual & Rede municipal & Rede privada & Total de matrículas \\
\hline 2007 & 275 & 27 & 262 & 564 \\
\hline 2008 & 266 & 0 & 261 & 527 \\
\hline 2009 & 227 & 0 & 133 & 360 \\
\hline 2010 & 212 & 0 & 129 & 341 \\
\hline 2011 & 186 & 0 & 127 & 313 \\
\hline 2012 & 169 & 0 & 124 & 293 \\
\hline 2013 & 137 & 0 & 122 & 259 \\
\hline 2014 & 156 & 0 & 119 & 275 \\
\hline 2015 & 115 & 0 & 155 & 270 \\
\hline
\end{tabular}

Fonte: elaboração própria com base nos dados do Instituto Nacional de Estudos e Pesquisas Educacionais Anisio Teixeira (INEP, 2016). 
Especial no Sistema Municipal de Ensino de Santa Maria (SANTA MARIA, 2011b) apresenta-se como um texto orientador da política pública que contempla a ação em todas as escolas municipais, com vistas a uma educação considerada de qualidade. Como afirmado anteriormente, na presente análise também foram utilizadas informaçóes concedidas mediante entrevistas com uma professora do atendimento educacional especializado e com o gestor de educação especial da Rede municipal de ensino de Santa Maria.

De acordo com o documento das diretrizes, o Sistema Municipal de Ensino de Santa Maria foi criado no ano de 1997, por meio da Lei Municipal no 4.123. Naquele momento, esse sistema era constituído dos seguintes segmentos: Secretaria de Município da Educação, Conselho Municipal de Educação, escolas municipais do ensino fundamental, instituições de educação infantil mantidas pelo poder público municipal e pela iniciativa privada e escolas de ensino profissionalizante (SANTA MARIA, 2011b).

Esse movimento encontra consonância com o processo de municipalização do ensino, iniciado após a publicação da Lei de Diretrizes e Bases da Educação Nacional (LDB) no 9.394/96 (BRASIL, 1996). Como aponta Prieto (2009), essa (re)definição de atribuiçóes obrigou os municípios a se ocuparem também da oferta do atendimento educacional aos alunos com deficiência pertencentes à educação infantil e ao ensino fundamental. Dessa forma, no contexto das diferentes redes municipais de ensino, foi criada e/ou mantida uma estrutura para a educação especial. As novas determinaçóes provocaram a reorganização das redes de ensino, tendo em vista o surgimento de novas demandas, competências e responsabilidades.

Pesquisas realizadas antes deste estudo enfatizaram ações públicas que contribuíram para a ampliação do número de matrículas de alunos em situação de inclusão, destacando-se o fechamento das classes especiais em 2007 e a elaboração das Diretrizes Curriculares Municipais em Educação Especial (BRIDI, 2011).

De acordo com as Diretrizes Curriculares para a Educação Especial no Sistema Municipal de Ensino de Santa Maria (SANTA MARIA, 2011b), a rede deu início a uma série de ações que envolve- 
ram: implementação de salas de recursos multifuncionais; formação de gestores, educadores e demais profissionais sobre a educação inclusiva; e produção e distribuição de recursos educacionais de acessibilidade. Com esses direcionamentos, um dos efeitos identificados foi a extinção das classes especiais nas escolas de ensino fundamental Duque de Caxias e Dom Antônio Reis (SANTA MARIA, 2011b, p. 20).

As ações descritas pelos integrantes da Secretaria de Município da Educação/Educação Inclusiva para a efetivação de políticas de inclusão escolar no sistema comum de ensino, em boa parte, estáo ligadas a programas do governo federal, como a implementação de salas de recursos, por intermédio do Programa Implantação de Salas de Recursos Multifuncional; formação de professores, com base no Programa Educação Inclusiva: Direito à Diversidade; formação de professores para o atendimento educacional especializado, mediante o Programa de Formação Continuada de Professores em Educação Especial; Programa Escola Acessível; e Programa Benefício de Prestação Continuada (BPC).

Em relação ao número de professores de educação especial no atendimento educacional especializado, de acordo com os dados do censo escolar de 2014, a rede municipal contava com 44 docentes. Como forma de ampliar o serviço de apoio à inclusão escolar no interior das escolas, além dos profissionais que atuavam nessa perspectiva, a rede municipal contava, em 2015, com 66 estagiários de inclusão escolar. Eram estudantes em processo de formação profissional, habitualmente alunos das licenciaturas, com prioridade para os cursos de Psicologia, Pedagogia e Educação Especial. As atribuiçóes desses estagiários envolviam os cuidados com locomoção, higiene e alimentação, e não necessariamente os processos de ensino-aprendizagem. A rede possuía, ainda, a característica de fornecer o transporte escolar a todos os alunos público-alvo da educação especial que necessitavam desse serviço.

Por último, no âmbito das ações desenvolvidas pelo município sobre os processos de inclusão escolar, o gestor de educação especial pontua a dificuldade presente na construção de parcerias com outras secretarias do município, como, por exemplo, a Secretaria de Saúde. A possibilidade de construir redes de trabalho auxiliaria até mesmo os postos de saúde a diminuírem suas listas de espera, pois muitas das crianças encaminhadas 
para uma avaliação clínica chegam a ficar até dois ou três anos aguardando atendimento. "Então, o que as escolas fazem, mandam pro [Programa de Atendimento Especializado Municipal] $\mathrm{PRAEM}^{8}$, para aproximarmos dentro da Secretaria da Saúde [...]" (Gestor de educação especial).

Uma dimensão importante diz respeito às diretrizes na ação dos professores especializados em educação especial, com destaque para o trabalho colaborativo previsto entre o professor de sala de aula e o docente especializado, que atua parte de seu tempo no espaço da sala de aula comum. Essas diretrizes se apresentam como uma linha organizadora da prática pedagógica desde a educação infantil. Trata-se de uma perspectiva descrita em diversos documentos normativos e orientadores, ressaltando o Plano Municipal de Educação, que se qualifica como um dos fundamentos para a garantia do acesso e da permanência dos estudantes público-alvo da educação especial, além da formação continuada dos professores para a atuaçáo colaborativa entre o atendimento educacional especializado e o ensino comum.

Quanto aos serviços especializados oferecidos por instituiçóes privadas (comunitárias, confessionais ou filantrópicas sem fins lucrativos) devidamente credenciadas, conforme Art. 29, $\$ 2^{\circ}$, da Resolução do Conselho Municipal de Educação de Santa Maria (CMESM) no 31/2011, eles devem ser "específico[s] para os serviços de Atendimento Educacional Especializado, no âmbito pedagógico, não permitindo a oferta das etapas e/ou modalidades da educação básica" (SANTA MARIA, 2011a, p. 11).

As parcerias com essas instituiçóes funcionam por meio de cedência de profissionais da rede pública, e, em contrapartida, jovens e adultos acima de 17 anos recebem atendimentos especializados em diversas áreas. Conforme prevê a legislação vigente, tais instituiçóes podem ofertar o atendimento educacional especializado aos alunos de 4 a 17 anos, de forma complementar à escolarização, tendo esse aluno matrícula obrigatória na rede regular de ensino.

Em relação aos alunos surdos, seguindo uma tendência do estado do Rio Grande do Sul, em que a escolarização tende a ocorrer em espaços exclusivos, tais alunos encontravam-se prioritariamente em uma escola especial da rede estadual. A influência da perspectiva teórica que 
defende a surdez como diferença tem respaldado a manutençáo desses espaços exclusivos.

\section{REFLEXÕES FINAIS}

Ao analisarmos a educação especial e a política de inclusão escolar em Santa Maria, evidencia-se que o município organiza suas açóes institucionais em sintonia com as políticas públicas nacionais, com iniciativas que indicam suas possibilidades locais, influências histórias e experiências. As marcas dessas trajetórias são perceptíveis tanto nos textos políticos quanto nos relatos dos gestores do município. Quando são analisados os índices de matrículas dos alunos com deficiência, percebem-se significativo aumento dessas matrículas no ensino regular e decréscimo nos indicadores relativos às matrículas em espaços de escolarização exclusiva (ensino especial), e a rede municipal não apresenta matrículas nesses espaços.

A concepção de política como texto e também discurso, apresentada no início do presente artigo, auxilia-nos na compreensão de que as distintas configuraçóes da política resultam nas singulares interpretaçóes dos textos, em um movimento que tende a confirmar que os próprios discursos são impregnados de história, poder e interesses.

Ao longo do texto, procuramos colocar em destaque nossa maneira de compreender o processo histórico constituidor das políticas, com base na valorizaçấo de relaçóes complexas e mutuamente dependentes. O que ocorre em um munícipio é, contemporaneamente, fruto de um processo mais amplo e, em modo simultâneo, elemento gerador de uma configuração geral. As múltiplas dimensôes dessa interação recíproca são o desafio central para a pesquisa, pois se mostram como uma pluralidade de influências difíceis de serem mapeadas. Nossa busca de fazer dialogar múltiplos indícios parte desse reconhecimento e da fidelidade aos pressupostos teórico-metodológicos apresentados.

A manutenção de espaços substitutivos públicos e privados, assim como a continuidade de financiamento dirigido às instituiçóes privadas conveniadas que atendem de forma exclusiva, representa o primeiro 
sinal de aparente ambiguidade em relação ao avanço do processo político de inclusão escolar. No caso de Santa Maria, a rede estadual ainda mantém classes especiais e uma escola especial para surdos, indicando que para alguns a escola regular ainda não seria o lugar preferencial.

O financiamento público de instituições privadas é mantido no munícipio pesquisado visando ofertar o atendimento educacional especializado complementar para alunos matriculados na rede regular que tenham idade superior àquela de matrícula obrigatória (17 anos), por meio de convênios que se manifestam na cedência de profissionais da rede municipal para a iniciativa privada.

Assim como evidenciado em outras localidades, a ampliação numérica dos profissionais de apoio à inclusão surge com diferentes tipologias, formas de contratação e atribuiçôes dos cargos. Merecedores de atenção e de futuros esclarecimentos vinculados à pesquisa, é o papel que cumprem os estagiários nesse processo, pois sua presença tem sido alvo de investimento. Por outro lado, a valorização do trabalho colaborativo, identificado como uma linha organizadora do trabalho pedagógico, salienta a necessária relação do ensino comum com o conhecimento especializado em educação especial. A singularidade dessa modalidade de interação profissional também precisa ser investigada, assim como seus efeitos.

Podemos, portanto, afirmar que a pesquisa nos permite identificar que essa rede pública implementou políticas de ampliação do acesso e de permanência de alunos com deficiência em classes comuns, instituindo serviços que buscam favorecer a escolarização desses alunos no ensino regular. Também vimos a existência de indícios de uma prática centrada no ensino colaborativo entre o atendimento educacional especializado e o ensino comum e a valorização de dispositivos que visam ao acesso ao currículo e à implementação de serviços de apoio associados à contratação de profissionais destinados a essas açóes.

\section{REFERÊNCIAS}

BALL, S. Education reform: a critical and post-structural approach. Buckingham: Open University Press, 1994. 
BALL, S.; MAINARDES, J. Políticas educacionais: questôes e dilemas. São Paulo: Cortez, 2011.

BAPTISTA, C.R. Ação pedagógica e educação especial: a sala de recursos como prioridade na oferta de serviços especializados. Revista Brasileira de Educação Especial, Marília, v. 17, p. 59-76, maio-ago. 2011. http://dx.doi.org/10.1590/ $\underline{\text { S1413-65382011000400006 }}$

(Org.). Escolarização e deficiência: configuraçôes nas políticas de inclusão escolar. São Carlos: Marquezine \& Manzini/ABPEE, 2015. Disponível em: \http://hdl.handle.net/10183/116627æ. Acesso em: 2 mar. 2018.

. Vestígios... pistas e relaçóes entre pensamento sistêmico e processos inclusivos. In: JESUS, D. M. et al. (Orgs.). Inclusão, práticas pedagógicas e trajetórias de pesquisa. 2. ed. Porto Alegre: Mediação, 2009. v. 1. p. 154-165.

BOWE, R.; BALL, S.; GOLD, A. Reforming education and changing schools: case studies in policy sociology. Londres: Routledge, 1992.

BRASIL. Conselho Nacional de Educação. Câmara de Educação Básica. Resoluçáo CNE/CEB no 04, de 2 de outubro de 2009, que institui Diretrizes Operacionais para o Atendimento Educacional Especializado na Educação Básica, modalidade Educação Especial. Brasília, 2 out. 2009.

. Lei no 9.394, de 20 de dezembro de 1996. Estabelece as Diretrizes e Bases da Educação Nacional. Diário Oficial da União. Brasília, 1996.

BRIDI, F. Processos de identificação e diagnóstico: os alunos com deficiência mental no contexto do atendimento educacional especializado. 210f. Tese (Doutorado em Educação) - Faculdade de Educação, Universidade Federal do Rio Grande do Sul, Porto Alegre, 2011.

BRIZOLLA, F. Políticas públicas de inclusão escolar: negociação sem fim. $221 f$. Tese (Doutorado em Educação) - Faculdade de Educação, Universidade Federal do Rio Grande do Sul, Porto Alegre, 2007.

INSTITUTO BRASILEIRO DE GEOGRAFIA E ESTATÍSTICA (IBGE). Estimativas populacionais para os municípios e para as Unidades da Federação brasileiros em 01.07.2015. Brasília: INEP, 2015. Disponível em: \https://www. ibge.gov.br/home/estatistica/populacao/estimativa2015 . Acesso em: 19 mar. 2018.

INSTITUTO NACIONAL DE ESTUDOS E PESQUISAS EDUCACIONAIS ANÍSIO TEIXEIRA (INEP). Microdados do Censo Escolar. Brasília: INEP, 2016. Disponível em: \http://portal.inep.gov.br/microdados $\geqq$. Acesso em: 2 mar. 2018. 
MATURANA, H.; VARELA, F.J. A árvore do conhecimento: as bases biológicas da compreensão humana. São Paulo: Palas Athena, 2001.

MULLER, P.; SUREL, Y. Análise das políticas públicas. Pelotas: EDUCAT, 2002.

PRIETO, R.G. Educação especial em municípios paulistas: histórias singulares ou tendência unificadora? In: BAPTISTA, C.; JESUS, D.M. (Orgs.). Avanços em Políticas de Inclusão: o contexto da educação especial no Brasil e em outros países. Porto Alegre: Mediação, 2009.

SANTA MARIA. Conselho Municipal de Educação de Santa Maria. Resolução $\mathrm{n}^{\circ} 29$, de 12 de setembro de 2011, que estabelece Diretrizes Educacionais para o Município de Santa Maria. Santa Maria, 21 nov. 2011a.

. Conselho Municipal de Educação de Santa Maria. Resolução no 31, de 12 de dezembro de 2011, que define Diretrizes Curriculares para a Educação Especial no Sistema Municipal de Ensino de Santa Maria. Santa Maria, 2011b.

\section{NOTAS}

1. Na escrita do presente texto, optamos pelo uso predominante da expressão alunos com deficiência por compreender que seja o grupo de maior número dentro daquele específico da Política Nacional de Educação Especial na Perspectiva da Educação Inclusiva de 2008, a qual identifica como público-alvo da educação especial os alunos com deficiência, transtornos globais do desenvolvimento, altas habilidades e superdotação.

2. Ao longo do presente texto, usamos os termos ensino regular para a referência às classes comuns de ensino regular e ensino especial para as classes especiais e escolas especiais.

3. Esses dados são sistematizados e disponibilizados de forma pública pelo Instituto Nacional de Estudos e Pesquisas Educacionais Anísio Teixeira (INEP), por meio do Educacenso, plataforma do censo escolar que representa a principal fonte de informação sobre a educaçáo básica no Brasil.

4. As falas dos entrevistados serão identificadas entre parênteses.

5. Vale salientar que um mesmo docente pode representar duas matrículas (dois contratos com a rede). Assim, no que tange ao tipo de contratação, o registro de matrículas do ano de 2013 mostra um número de 2.937 concursados, 54 contratos temporários e 41 contratados no regime da Consolidaçáo das Leis do Trabalho (CLT).

6. Embora tenha havido a busca no âmbito dos microdados do censo escolar da educação básica (Ministério da Educação/INEP) relativo ao banco de docentes envolvendo os anos de 2014 e 2015, o sistema mostrou-se inconsistente. 
7. Como apoio complementar ao corpo docente, existe a figura do auxiliar/assistente educacional, que, no ano de 2013, computava 94 matrículas na etapa da educação infantil e 46 no ensino fundamental.

8. O Programa de Atendimento Especializado Municipal (PRAEM) existe desde 2010 e tem como objetivo oferecer apoio especializado aos alunos da rede municipal de ensino de Santa Maria no que concerne à caracterizaçáo, ao desenvolvimento de estratégias e ao acompanhamento dos processos educativos.

Recebido em 15 de maio de 2018.

Aprovado em 2 de agosto de 2018. 